\title{
Relaçoes compliance da missão institucional e a utilização de indicadores de desempenho não financeiros em empresas listadas na B3
}

\section{Antonio Andre Cunha Callado, Diengo Dantas Siqueira}

Universidad Federal Rural de Pernambuco - Brasil

Universidad Federal da Paraíba - Brasil

O presente estudo teve como objetivo investigar a associação entre o compliance da missão institucional das empresas brasileiras de capital aberto e a utilização de indicadores de desempenho não financeiros. Para atingir o objetivo proposto foi operacionalizada uma pesquisa descritiva e quantitativa, considerando empresas não financeiras listadas na B3. A missão institucional foi mensurada com base nas características propostas nos estudos de Pearce e David (1987) e David (1989). Já os indicadores de desempenho não financeiros foram mensurados com base na pesquisa Marquezan, Diehl e Alberton (2013), e Vargas Diehl, Ayres, \& Monteiro (2016). Dados referentes a nove características associadas à missão, bem como a indicadores não financeiros pertencentes a oito distintos grupos foram coletados nos relatórios anuais e sites institucionais das empresas por meio da análise de conteúdo. A amostra probabilística consistiu em 115 empresas referentes ao exercício fiscal de 2018. A análise da significância das relaçóes foi realizada usando a Prova Exata de Fisher. Os resultados encontrados mostraram evidências acerca da presença de relaçóes entre o compliance da missão institucional e indicadores de desempenho não financeiros, indicando que as empresas analisadas fazem uso destes indicadores para acompanhar o compliance das declarações expressas na missão. Em termos práticos, este estudo contribui ao reforçar a relevância da missão institucional para o alcance dos objetivos e estratégias empresariais e demonstrar que os indicadores de desempenho não financeiros podem ser preferíveis para acompanhar se aquilo que foi declarado na missão está sendo alcançado. Uma nova perspectiva sobre a análise de indicadores não financeiros, foi inserida no contexto das pesquisas que analisam a relação entre missão e desempenho, trazendo contribuiçóes teóricas e fornecendo novos insights para discussôes relacionadas ao tema.

Palavras-chave: compliance, indicadores de desempenho não financeiros, missão institucional, empresas de capital aberto

\section{Compliance relations of the institutional mission and the use of non-financial performance indicators in companies listed on B3}

This paper aims to investigate the association between the compliance of the institutional mission of open capital Brazilian companies and the use of non-financial performance indicators. To achieve this goal, it was operationalized a descriptive and quantitative research, considering non-financial companies listed on B3. The institutional mission was measured based on the characteristics proposed by Pearce \& David (1987) and David (1989) studies. Likewise, the indicators of non-financial performance were measured based on the research realized by Marquezan, Diehl and Alberton (2013) and Vargas, Diehl, Ayres, \& Monteiro (2016). Data referring to nine characteristics associated to mission, as well as nonfinancial indicators of eight distinct groups were collected in annual reports and institutional websites from the companies by the content analysis. The probabilistic sample consisted in 115 companies referring to the fiscal year of 2018. The significance analysis of the relations was realized using Fisher's Exact Test. The results found showed evidence concerning the presence of relations between the compliance of the institutional mission and non-financial performance indicators, 
suggesting that the analyzed companies make use of these indicators to track the compliance of the declarations expressed in the mission. In practical terms, this study contributes by reinforcing the relevance of the institutional mission to the achievement of entrepreneurial objectives and strategies and by demonstrating that the non-financial performance indicators may be preferable in order to monitor whether what was stated in the mission is being achieved. A new perspective on the analysis of non-financial indicators was inserted in the context of researches that analyze the relation between mission and performance, bringing theoretical contributions and providing new insights for discussions related to the topic.

Keywords: compliance, non-financial performance indicators, institutional mission, open capital companies

\section{Relaciones compliance de la misión institucional y utilización de indicadores de rendimiento no financieros en empresas listadas en B3}

El presente estudio tuvo como objetivo investigar la asociación entre el compliance de la misión institucional de las empresas brasileñas de capital abierto y la utilización de indicadores de desempeńo no financieros. Para alcanzar el objetivo propuesto, se realizó una investigación descriptiva y cuantitativa, considerando las empresas no financieras enumeradas en B3. La misión institucional se valoró sobre la base de las características propuestas en los estudios de Pearce y David (1987), y David (1989). Por otra parte, los indicadores de desempeńo no financieros fueron medidos de acuerdo con la encuesta Marquezan, Diehl y Alberton (2013), y Vargas, Diehl, Ayres y Monteiro (2016). Los datos relativos a nueve características asociadas a la misión, así como a indicadores no financieros pertenecientes a ocho distintos grupos fueron recogidos en los informes anuales y sitios institucionales de las empresas por medio del análisis de contenido. La muestra probabilística incluyó 115 empresas para el ejercicio fiscal de 2018. El análisis de la significatividad de las relaciones se realizó usando la prueba exacta de Fisher. Los resultados encontrados mostraron evidencia acerca de la presencia de relaciones entre el compliance de la misión institucional e indicadores de desempeño no financieros. De esta manera, se evidencia que las empresas analizadas hacen uso de estos indicadores para acompañar el compliance de las declaraciones expresadas en la misión. En términos prácticos, este estudio contribuye a reforzar la relevancia de la misión institucional para el logro de los objetivos y estrategias empresariales, y demostrar que los indicadores de desempeńo no financieros pueden ser preferibles para controlar si lo declarado en la misión se está alcanzando. Una nueva perspectiva sobre el análisis de indicadores no financieros fue insertada en el contexto de las investigaciones que analizan la relación entre misión y desempeño. Así, se proponen contribuciones teóricas y se proporcionan nuevos insights para discusiones relacionadas al tema.

Palabras clave: compliance, indicadores de desempeño no financieros, misión institucional, empresas de capital abierto

\section{Introduçáo}

Comunicar de forma clara e concisa, prioridades, valores e crenças de uma empresa, para que todos os colaboradores possam buscar objetivos comuns é uma prática importante, tendo em vista que é através das crenças, desejos e aspiraçóes que ela nasce e se desenvolve (Santos, Camacho \& Junqueira, 2019). Neste contexto, a missão institucional tem se mostrado como uma importante ferramenta para gestão
(Mussoi, Lunkes \& Da Silva, 2011; Coral, Souza \& Lunkes, 2013). A missão institucional de uma empresa pode ser definida como uma declaração abrangente e duradoura de sua finalidade, evidenciando o produto ou serviço, mercados, clientes, assim como sua filosofia (Pearce \& David, 1987, p. 109). Quando bem definida, ela engloba todas as características cruciais (King, Case \& Premo, 2012). A missão institucional, quando declarada pela empresa, descreve seus objetivos e suas aspiraçóes para o futuro, sendo essenciais para o 
crescimento sustentado (Green \& Medlin, 2003; Punniyamoorthy \& Murali, 2008), bem como expressa sua razão para existir (Ribeiro \& Carmo, 2015).

Por se tratar de uma ferramenta de gestão, a missão deve ser coerente com as açóes organizacionais (Santos et al., 2019) e servir como referência orientadora no estabelecimento de objetivos, estratégias e metas (Bartkus, Glassman \& McAfee, 2006). Além disso, a missão deve ser específica o suficiente permitindo que a empresa acompanhe a execução de seus objetivos (Ribeiro \& Carmo, 2015), independentemente do porte ou do setor de atividade (Araújo, De Souza Michelon, \& Lunkes, 2018).

Outro instrumento gerencial empresarial importante é a mensuração de desempenho. Para Callado, Callado e Mendes (2015), esta é uma ferramenta estratégica que pode fornecer informaçóes centrais para gestấo, $\mathrm{e}$ permite conhecer a situação da empresa com relaçáo às metas estabelecidas. Além disso, a mensuração de desempenho permite identificar deficiências nas operaçóes (Martins, Girão, Da Cunha \& Araújo, 2013), bem como alinhar práticas das empresas com os objetivos estratégicos (Müller, 2003).

Buscando um maior alinhamento entre açóes desempenhadas por colaboradores e o compliance (cumprimento) dos objetivos estabelecidos na missão, empresas têm feito uso de indicadores de desempenho com o intuito de avaliar esses processos (Gonzaga, Cruz, Pereira \& Luz, 2015). Desta forma, os indicadores de desempenho auxiliam os gestores a acompanhar as operaçóes e os colaboradores, para verificar se está havendo o compliance das diretrizes internas da empresa expressas em sua missão institucional.

A partir do entendimento de que a missão informa aonde a empresa quer chegar e que os indicadores de desempenho possibilitam a verificação do compliance desses objetivos, pode-se assumir que estas ferramentas sejam complementares (Gonzaga et al., 2015), sugerindo a possibilidade de alinhamento entre a missão institucional e os indicadores de desempenho. No entanto, a literatura apresenta poucos estudos anteriores relacionados a este eixo investigativo.

No contexto nacional, pesquisas relacionadas ao tema têm focado em verificar se as empresas apresentam os elementos propostos por Pearce II (1982) em suas missôes, como forma de sinalizar um planejamento estratégico efetivo (Mussoi et al., 2011; Coral et al., 2013; Lugoboni, Mello, Fischman, Quishida, Zittei, 2019; Araújo et al., 2018), investigar se existem indícios de responsabilidade socioambiental na missão, visão e valores das organizaçóes (Oliveira, Portella, Ferreira \& Borba, 2016), bem como os fatores que podem influenciar sua efetividade (Martins, Diehl \& Brunozi Junior, 2018).

No contexto internacional, as pesquisas têm dado a atenção para a relação entre as declaraçóes de missão e o desempenho financeiro (Bart, 1997; Bart \& Baetz, 1998; Bartkus et al., 2006; Green \& Medlin, 2003; Duygulu, Ozeren, Işıldar \& Appolloni, 2016). Recentemente, Gonzaga et al., (2015), conduziram uma pesquisa nesse sentido, investigando possíveis associações entre a missão declarada e os indicadores de desempenho financeiros, contribuindo para um melhor entendimento sobre o assunto.

No entanto, medidas financeiras tradicionais de desempenho tem sido alvo de diversas críticas pela literatura por evidenciarem eventos já ocorridos, encorajando uma visão de curto prazo, e fornecendo pouca orientação estratégica voltada para o futuro (Kaplan \& Norton, 1992; Bourne, Mills, Wilcox, Neely, \& Platts, 2000). Por outro lado, indicadores não financeiros auxiliam os gestores a focarem suas açōes em uma perspectiva de longo prazo, orientando melho- 
rias nos processos em toda a empresa, alavancando sua competitividade (Diehl, Rech \& Martins, 2015). Sobre isso, Punniyamoorthy e Murali (2008) comentam que a missão declarada pelas empresas, apresenta suas aspiraçóes para o futuro, e é estratégica para o crescimento sustentado. Contudo, os autores relatam que os princípios que surgem de suas estratégias, não podem ser totalmente capturados em nenhum tipo de sistema tradicional.

Desse modo, como a missão institucional fornece uma visão de longo prazo, voltada para o futuro, parece mais coerente que as empresas façam uso de indicadores não financeiros para acompanhar se a missão está sendo alcançada. Tendo, em vista que os indicadores não financeiros vêm sendo apontados pela literatura como impulsionadores de melhorias organizacionais (Marquezan, Diehl, \& Alberton, 2013; Diehl et al., 2015), contribuindo para o sucesso ao longo prazo (Martins, 2006).

Portanto, diante da discussão realizada, surge o seguinte questionamento de pesquisa: Qual a associação entre o compliance da missáo institucional das empresas brasileiras de capital aberto e a utilizaçáo de indicadores de desempenho náo financeiros? Assim, o objetivo deste artigo consiste em investigar a associaçáo entre o compliance da missão institucional das empresas brasileiras de capital aberto e a utilização de indicadores de desempenho não financeiros.

Desse modo, esta pesquisa apresenta algumas contribuiçóes relevantes dos pontos de vista teórico e prático. Primeiro, a pesquisa contribui ao analisar a efetividade das declaraçóes de missóes das companhias abertas brasileiras conforme Pearce e David (1987) e David (1989), e ao verificar os indicadores de desempenho não financeiros evidenciados e utilizados por parte destas companhias.
Segundo, a pesquisa avança na literatura ao fornecer resultados empíricos sobre a associação entre a missão declarada pelas empresas e os indicadores de desempenho não financeiros utilizados. Pois, como citado anteriormente, os estudos desenvolvidos até então têm se concentrado na análise de indicadores financeiros. Existindo, portanto, uma importante lacuna a ser investigada, considerando que não foram encontradas pesquisas que analisaram indicadores não financeiros.

Terceiro, do ponto de vista prático, este trabalho contribui ao reforçar para as empresas a relevância da missão institucional como elemento central no planejamento estratégico. Visto que, a divulgação de missóes efetivas pode ter implicaçóes importantes dentro da organização, devendo as empresas acompanharem sua execução. Uma vez que, o acompanhamento é crucial para se atingir os objetivos (Müller, 2003). Por fim, esta pesquisa contribui ao fornecer base para que as empresas possam refletir sobre a missão evidenciada e desenvolver novas ferramentas (bem como aprimorar as existentes) para que estas permitam acompanhar de forma efetiva, os objetivos estratégicos da organização.

\section{Revisão da literatura}

\subsection{Compliance}

Compliance está relacionado ao comprometimento de todos que fazem parte da empresa, em buscar atender aos interesses das partes e as regras preestabelecidas, considerando a ética e integridade empresarial (Melo \& Lima, 2019a). Refere-se ao dever de cumprir as normas internas e externas a que a empresa está exposta, buscando a minimização de riscos legais e riscos capazes de afetar a reputação da empresa (Morais, 2005), sendo visto, inclusive, como uma estratégia aplicável a todas as empresas, bem como capaz de reduzir desvios de conduta dos seus membros e refletir a ideia 
de comprometimento ético e organizacional (Costa, 2012; Ribeiro \& Diniz, 2015).

A necessidade da atividade de compliance surge da busca por parte das empresas pela aderência as melhores práticas, exigências legais e normas internas, onde, para seu alcance, faz-se necessário que haja o monitoramento acerca do cumprimento dessas exigências (Perera, Freitas \& Imoniana, 2014). Portanto, com a implantação da política de compliance, a organização busca orientar suas açóes para os objetivos estabelecidos (Ribeiro \& Diniz, 2015).

É possível afirmar que ocorre compliance quando o comportamento real dos colaboradores da empresa está de acordo com o comportamento esperado, previamente estabelecido. Por outro lado, não compliance ocorre quando o comportamento real, não está em conformidade com o que se espera de seus membros (Young, 1979). Desse modo, a atividade de compliance busca de certa forma, alinhar os interesses de todos que fazem parte da empresa para o alcance dos objetivos comuns, orientando a instituição e atitude dos seus funcionários (Candeloro, Rizzo, Pinho, 2012), de modo a assegurar o cumprimento de todas as normas aplicáveis a organização (Miller, 2014) e proporcionar uma cultura de integridade organizacional (Melo \& Lima, 2019a).

Quando políticas de compliance são implementadas, as empresas fazem uso de ferramentas que buscam garantir o atendimento do que é estabelecido pelas diretrizes internas da organização, como valores e regras de conduta, assim, como regulamentos externos à empresa, como leis estabelecidas por órgãos reguladores (Schramm, 2015). Assim, verifica-se que os indicadores de desempenho se mostram como ferramentas úteis para assegurar o compliance das diretrizes estabelecidas na missão. Tendo em vista que, os indicadores de desempenho possibilitam avaliar as ações realizadas dentro da empresa e auxiliam a acompanhar se o que foi planejado está sendo alcançado (Müller, 2003; Marquezan et al., 2013; Diehl et al., 2015).

No entanto, para ser mais efetivo, faz-se necessário que o programa de compliance também englobe aspectos comportamentais, relacionados aos valores individuais dos membros e da empresa (Santos, Guevara, Amorim, \& Ferraz-Neto, 2012). Tentando motivar seus colaboradores desde o alto escalão, até as funções mais baixas, para que atuem de acordo com as regras internas e externas (Assi, 2013; Silva, Melo, \& Sousa, 2020), tendo em vista que o sucesso do compliance relaciona-se também ao comprometimento dos membros da organização para cumprir as determinações (Melo \& Lima, 2019b).

Desse modo, apesar de inicialmente parecer estar associado apenas à questáo de conformidade, o compliance compreende uma disciplina muito abrangente, que engloba a forma de atuação da empresa considerando seus negócios, operaçóes e pessoas (Wanderer, 2017), não podendo, portanto, ser confundido com o simples ato de cumprir regras formais e informais (Ribeiro \& Diniz, 2015). Considerando essa visão mais abrangente, o compliance se mostra como ferramenta que auxilia no alcance da missão da empresa (Candeloro et al., 2012; Ribeiro \& Diniz, 2015). Dessa forma, tem-se que a missão institucional é parte integrante do processo de compliance (Costa, 2012), devendo, portanto, haver a verificação das medidas que estáo sendo realizadas para alcançar os objetivos declarados na missão.

Com isso, entende-se que a atividade de compliance se apresenta como uma ferramenta gerencial para assegurar que todos os colaboradores de uma determinada empresa busquem alcançar os objetivos estabelecidos na missão institucional. Tendo em vista que, o 
compliance tem sido apontado como uma ferramenta estratégica, capaz de auxiliar no gerenciamento dos negócios e alcance dos objetivos (Assi, 2013; Silva \& Covac, 2015).

\subsection{Indicadores de desempenho}

Tradicionalmente, a avaliação de desempenho tem sido utilizada como um instrumento de mensuração da eficiência e eficácia das atividades empresariais (Vargas Diehl, Ayres, \& Monteiro, 2016). Que visa auxiliar a implementação e monitoramento de iniciativas estratégicas. A medição de desempenho permite aos gestores acompanhar como a empresa está realizando as operaçóes planejadas, assim como controlá-las (Martins et al., 2013).

Hronec (1994) comenta que, a implementação de um sistema de avaliação de desempenho permite as organizaçóes alcançarem algumas vantagens, dentre as quais pode-se citar o alinhamento das pessoas com os objetivos estratégicos e a missão da organização, desempenho eficaz e eficiente no longo prazo, oportunidades de monitorar seus processos e instituir melhorias contínuas, dentre outras possibilidades. Para a avaliação do desempenho é necessário a utilização de indicadores que irão dar suporte a organização a focar no alcance dos seus objetivos estratégicos (Bourne et al., 2000). Os indicadores de desempenho permitem que a organizaçáo quantifique suas atividades e informam quando atingem uma meta específica (Callado et al., 2015).

Estes indicadores são comumente classificados como financeiros e não financeiros. De forma resumida, os indicadores financeiros (também chamados de tradicionais) fornecem orientação para decisôes relacionadas a questôes econômicas e patrimoniais, já os indicadores não financeiros vão além dos aspectos quantitativos e auxiliam na orientação de melhorias nos processos em toda organização (Marquezan et al., 2013). Permitindo aos gestores focarem suas açóes em uma perspectiva de longo prazo (Atkinson, Banker, Kaplan, Young, 2000; Diehl et al., 2015).

Como exemplos de indicadores financeiros pode-se citar o faturamento, a lucratividade líquida, retorno do capital investido, grau de endividamento, já em relação aos indicadores não financeiros tem-se a satisfação de clientes, a participação no mercado, a qualidade dos produtos, retenção e fidelidade dos clientes, o comprometimento ambiental, bem como os aspectos sociais (Wernke \& Junges, 2017). Ainda segundo estes autores, os indicadores não financeiros podem ser considerados ferramentas estratégicas para a gestão empresarial e para a criação de vantagens competitivas.

Diante do exposto, observa-se que os indicadores de desempenho representam uma ferramenta muito importante para o controle organizacional (Callado, Callado \& Almeida, 2008). Que permite mensurar em ponto a empresa está em relação às metas estabelecidas, assim como, os resultados de suas açóes (Callado, Callado \& Almeida, 2012; Callado et al., 2015; Wernke \& Junges, 2017). E, portanto, permitem avaliar o compliance dos objetivos e metas evidenciados na missão institucional (Gonzaga et al., 2015). Visto que, um dos objetivos da avaliaçáo de desempenho, por meio de seus indicadores, é verificar se a missão da empresa está sendo alcançada (Marquezan et al., 2013).

A este respeito, Müller (2003) sugere que após a definição da missão, surge a necessidade de acompanhamento para verificar se ela está sendo cumprida. Para tanto, o autor explica que a avaliaçáo de desempenho surge como ferramenta de destaque, visto que para ter sucesso no longo prazo um bom planejamento estratégico não é suficiente, sendo necessário que o plano definido seja cumprido.

Contabilidad y Negocios (16) 32, 2021 / ISSN 1992-1896 
Contudo, como a missão institucional apresenta uma perspectiva de longo prazo, acredita-se que adoção de indicadores financeiros para avaliar o seu compliance não seja suficiente (Punniyamoorthy \& Murali, 2008). Dessa forma, pelas suas características, principalmente o foco no longo prazo (Bourne et al., 2000; Vargas et al., 2016; Diehl et al., 2015), os indicadores de desempenho não financeiros podem ser os mais indicados para que as organizações possam alinhar suas práticas organizacionais aos objetivos estratégicos evidenciados na missão.

\subsection{Estudos anteriores}

A literatura que envolve missão institucional emergiu por volta de 1980 e, desde então, o tema vem se desenvolvendo em diversas perspectivas (Alegre, Berbegal-Mirabent, Guerrero, \& Mas-Machuca, 2018). Para uma maior compreensão a respeito do tema abordado, buscaram-se algumas pesquisas que investigaram aspectos relacionados a missão institucional e relacionados aos indicadores de desempenho. Com destaque para os estudos que analisaram as relaçóes entre estes dois aspectos. A tabela 1 evidencia os autores analisados, os objetivos das pesquisas, bem como os principais resultados encontrados.

De forma geral, acredita-se que, a missão institucional declarada pelas empresas se associa positivamente aos indicadores de desempenho financeiros. Contudo, não foram identificadas pesquisas que analisassem indicadores de desempenho não financeiros. Assim, considerando que a missão evidencia os principais objetivos da organização, principalmente o de longo prazo, acredita-se que indicadores de desempenho náo financeiros podem auxiliar as empresas a verificarem se os objetivos evidenciados estão sendo alcançados. Formulando-se, assim, a seguinte hipótese a ser testada:

H1: Há uma associação positiva entre a missão institucional e os indicadores de desempenho não financeiros.

\section{Tabela 1. Estudos sobre missão institucional e desempenho}

\begin{tabular}{|c|c|c|}
\hline Autor/Ano & Objetivo & Principais resultados \\
\hline $\begin{array}{l}\text { Bart \& Baetz } \\
\quad(1998)\end{array}$ & $\begin{array}{l}\text { Examinar a relaçáo entre declaraçóes de missão e } \\
\text { desempenho financeiro usando uma amostra de } 136 \\
\text { grandes organizaçốes canadenses. }\end{array}$ & $\begin{array}{l}\text { Os resultados do estudo demonstram que as declaraçóes de mis- } \\
\text { são e algumas de suas características específicas estão seletivamente } \\
\text { associadas a níveis mais altos de desempenho organizacional. }\end{array}$ \\
\hline $\begin{array}{l}\text { Green \& } \\
\text { Medlin } \\
(2003)\end{array}$ & $\begin{array}{l}\text { Investigar a ligaçáo entre a integridade e a qualidade } \\
\text { da declaraçáo de missáo e os indicadores de desem- } \\
\text { penho (financeiro, mercado, produçáo e geral). }\end{array}$ & $\begin{array}{l}\text { Os resultados demonstram uma relação positiva e significativa } \\
\text { entre a integridade e a qualidade da missão e o desempenho } \\
\text { financeiro da organizaçáo. }\end{array}$ \\
\hline $\begin{array}{l}\text { Biloslavo } \\
(2004)\end{array}$ & $\begin{array}{l}\text { Foram analisadas as declaraçóes de missão das } 50 \text { prin- } \\
\text { cipais empresas eslovenas com os seguintes objetivos: i) } \\
\text { estabelecer o grau em que as empresas eslovenas fazem } \\
\text { uso de seus sites para transmitir sua missão a várias } \\
\text { partes interessadas, ii) identificar os grupos de partes } \\
\text { interessadas que são mencionados nas declarações de } \\
\text { missão, e iii) analisar o conteúdo dessas declarações. }\end{array}$ & $\begin{array}{l}\text { Verificou-se a existência de algumas diferenças significativas entre } \\
\text { as missóes analisadas e as de outras empresas europeias ou ameri- } \\
\text { canas. Os autores apontam que as razóes para essas diferenças são } \\
\text { culturais, institucionais e históricas. Os autores concluem que ape- } \\
\text { sar dos processos de globalização e regionalização, a convergência } \\
\text { de vários conteúdos da declaração de missão é questionável. }\end{array}$ \\
\hline $\begin{array}{l}\text { Bartkus et al. } \\
\quad(2006)\end{array}$ & $\begin{array}{l}\text { Analisar a relação da qualidade da declaração de } \\
\text { missáo com o desempenho financeiro. }\end{array}$ & $\begin{array}{l}\text { Os resultados apontam que a maioria dos elementos nas decla- } \\
\text { raçốes de missão não estão associada ao desempenho da empresa. } \\
\text { Contudo, declaraçóes de missáo que incluem frases que se refe- } \\
\text { rem as regras fundamentais dos negócios têm uma relação positiva } \\
\text { significativa com o desempenho financeiro, essas regras incluem: } \\
\text { preocupe-se com seus funcionários, seja responsável perante a } \\
\text { sociedade, enfatize e comunique seu valor. }\end{array}$ \\
\hline
\end{tabular}




\begin{tabular}{|c|c|c|}
\hline Autor/Ano & Objetivo & Principais resultados \\
\hline $\begin{array}{l}\text { Mussoi et al. } \\
\quad(2011)\end{array}$ & $\begin{array}{l}\text { Avaliar os elementos das missóes institucionais das } \\
\text { companhias de capital aberto no Brasil. }\end{array}$ & $\begin{array}{l}\text { Verificaram que os principais elementos contidos nas missóes das } \\
\text { empresas brasileiras foram: clientes, produtos ou serviços e con- } \\
\text { texto ou mercado de atuaçáo. Em relaçáo à efetividade, a maioria } \\
\text { das empresas (50) apresenta apenas três dos oito elementos pro- } \\
\text { postos por Pearce (1982). }\end{array}$ \\
\hline $\begin{array}{l}\text { King et al. } \\
(2012)\end{array}$ & $\begin{array}{l}\text { Realizaram a comparação do conteúdo das decla- } \\
\text { raçóes de missão das } 25 \text { maiores empresas da França, } \\
\text { Alemanha, Japão e China em relação às } 25 \text { maiores } \\
\text { empresas dos Estados Unidos. }\end{array}$ & $\begin{array}{l}\text { São apresentados uma série de resultados relevantes, dentre os } \\
\text { quais destaca-se o fato de que as grandes organizaçóes em cada um } \\
\text { desses países percebem os clientes como a parte interessada mais } \\
\text { importante. Os clientes foram mencionados em mais declaraçóes } \\
\text { de missão do que qualquer outra parte interessada, incluindo fun- } \\
\text { cionários, acionistas, comunidades e fornecedores. Além disso, em } \\
\text { geral, os objetivos mais comumente declarados foram a produção } \\
\text { de um produto ou serviço de qualidade e o fornecimento desse } \\
\text { produto ou serviço em uma base global. }\end{array}$ \\
\hline $\begin{array}{l}\text { Marquezan } \\
\text { et al., (2013) }\end{array}$ & $\begin{array}{l}\text { Identificar quais as medidas não financeiras de ava- } \\
\text { liaçấo de desempenho são utilizadas e divulgadas } \\
\text { pelas principais empresas participantes do índice } \\
\text { IBOVESPA. }\end{array}$ & $\begin{array}{l}\text { Foram encontrados indicadores não financeiros em todos os rela- } \\
\text { tórios analisados, com destaque para os que avaliam ou medem } \\
\text { os processos das empresas e sua gestão de recursos humanos. Os } \\
\text { autores explicam que isso ocorre por possuírem a maior diversi- } \\
\text { dade de indicadores, enquanto os que avaliam o desempenho de } \\
\text { produção e venda de produtos sáo os mais abordados; porém, a } \\
\text { maioria sáo variaçóes do mesmo índice. }\end{array}$ \\
\hline $\begin{array}{l}\text { Gonzaga et al. } \\
(2015)\end{array}$ & $\begin{array}{l}\text { Verificar se há associação entre as missóes declaradas } \\
\text { pelas empresas brasileiras e os indicadores de desem- } \\
\text { penho financeiros que utilizam. }\end{array}$ & $\begin{array}{l}\text { Não foi encontrada associação entre as características das missóes } \\
\text { declaradas pelas empresas e os indicadores de desempenho por elas } \\
\text { utilizados. }\end{array}$ \\
\hline $\begin{array}{l}\text { Duygulu et al. } \\
\quad(2016)\end{array}$ & $\begin{array}{l}\text { Identificar as características presentes nas declaraçóes } \\
\text { de missão e visão das Pequenas e Médias empresas tur- } \\
\text { cas e avaliar o impacto no desempenho organizacional. }\end{array}$ & $\begin{array}{l}\text { Os resultados mostram que três características da missão: (1) sobre- } \\
\text { vivência, crescimento e lucro; (2) filosofia e valores; e (3) imagem } \\
\text { pública, estáo associadas positivamente ao desempenho das PME. }\end{array}$ \\
\hline $\begin{array}{l}\text { Vargas et al. } \\
\quad(2016)\end{array}$ & $\begin{array}{l}\text { Identificar quais as medidas não financeiras de ava- } \\
\text { liação de desempenho divulgadas pelas empresas do } \\
\text { setor de telecomunicaçóes listadas na BOVESPA. }\end{array}$ & $\begin{array}{l}\text { Verificou-se a presença de indicadores não financeiros em todos os } \\
\text { relatórios analisados. Destacam-se a maior presença de indicado- } \\
\text { res que avaliam ou medem as questóes relacionados aos recursos } \\
\text { humanos por possuírem o maior número de indicadores, seguidos } \\
\text { pelos referentes às questóes ambientais. Além disso, o indicador } \\
\text { que mede o índice de satisfaçáo dos clientes com a prestação dos } \\
\text { serviços é utilizado em todas as empresas analisadas bem como o } \\
\text { número de reclamaçóes. }\end{array}$ \\
\hline $\begin{array}{l}\text { Martins et al. } \\
\quad(2018)\end{array}$ & $\begin{array}{l}\text { Avaliar a efetividade das declaraçóes de missóes, } \\
\text { conforme o modelo de Pearce e David (1987), e sua } \\
\text { relação com os fatores contingenciais das empresas } \\
\text { dos países GLENIF. }\end{array}$ & $\begin{array}{l}\text { Foi encontrada relação positiva e estatisticamente significativa entre } \\
\text { a estratégia a efetividade das declaraçóes de missão. Verificou-se } \\
\text { ainda que nenhuma das missóes apresentaram todos os oito elemen- } \\
\text { tos do modelo, de modo que a maioria delas possui entre dois e qua- } \\
\text { tro elementos. Dentre estes destaca-se o serviço oferecido e conceito } \\
\text { próprio, encontrados em mais de } 70 \% \text { das missóes analisadas. }\end{array}$ \\
\hline $\begin{array}{l}\text { Lugoboni et } \\
\text { al. (2019) }\end{array}$ & $\begin{array}{l}\text { Identificar como é a missão das empresas classifica- } \\
\text { das como "maiores e melhores" no Brasil. }\end{array}$ & $\begin{array}{l}\text { Constataram que os aspectos mais presentes na missáo foram a } \\
\text { identificaçáo do autoconceito e valores fundamentais, filosofia, } \\
\text { tecnologias e competências e comportamentos essenciais da orga- } \\
\text { nização; produtos e serviços; e questóes de sustentabilidade (social } \\
\text { e ambiental). }\end{array}$ \\
\hline
\end{tabular}

Fonte: Bart \& Baetz (1998), Green \& Medlin (2003), Biloslavo (2004), Bartkus et al. (2006), Mussoi et al. (2011), King et al. (2012), Marquezan et al., (2013), Gonzaga et al. (2015), Duygulu et al. (2016), Vargas et al. (2016), Martins et al. (2018) Lugoboni et al. (2019). 


\section{Procedimentos metodológicos}

Para atingir o objetivo proposto para esta pesquisa, foi realizada uma pesquisa descritiva e quantitativa. Pesquisas descritivas buscam apresentar características e comportamentos de uma população específica, elaborada com a finalidade de verificar possíveis relaçóes entre variáveis (Gil, 2017). Quanto a abordagem do problema, a pesquisa é tida como quantitativa. Martins e Theóphilo (2009), explicam que, a pesquisa é classificada como quantitativa quando se pode atribuir valor aos dados coletados, assim, esses dados são organizados e tabulados para que possam ser realizados procedimentos estatísticos, permitindo a interpretação. Com relação aos procedimentos, trata-se de uma pesquisa documental, tendo em vista que, foram utilizados dados secundários coletados nos sites das empresas analisadas (Gil, 2017).

A população da pesquisa é composta por todas as empresas não financeiras listadas na Brasil, Bolsa e Balcáo (B3) em outubro de 2019, totalizando 309 empresas. O período de estudo engloba o ano de 2018, isso porque a declaração de missão empresarial não é um documento de divulgação anual. Ao que diz respeito a amostra, esta pesquisa fez uso da amostragem probabilística, pois os elementos da amostra foram selecionados com probabilidades conhecidas (Martins \& Theóphilo, 2017). Desse modo, para definir a amostra, foi realizado o cálculo do tamanho da amostra representativa de uma população finita. O tamanho amostral (n) foi calculado considerando o nível de confiança de 95\% (erro amostral de 5\%). Resultando, portanto, em uma amostra de 172 empresas não financeiras representativas da população. Em seguida, estas empresas foram identificadas utilizando abordagem randômica, por meio dos números aleatórios, utilizando os recursos de uma planilha eletrônica.
Além disso, foram excluídas as empresas que não apresentaram dados suficientes para composição das variáveis no período analisado (especificamente as empresas que não evidenciaram a missão institucional em seu site/relatórios). Restando, portanto, uma amostra de 115 organizaçóes para o ano de 2018. Para o delineamento das características presentes nas missóes, assim como para os indicadores de desempenho, foi utilizada a técnica de análise de conteúdo. Como apontado por Bardin (2011) consiste em "um conjunto de técnicas de análises de comunicaçóes que utiliza procedimentos sistemáticos e objetivos de descrição do conteúdo das mensagens" (p. 44). Ainda, segundo o autor, essa análise se dá em três etapas: pré-análise; exploração do material; e tratamento dos resultados.

Os dados foram coletados de duas formas, informaçôes referentes a missão institucional foram coletadas nos sites das empresas, em seus relatórios anuais e de sustentabilidade. Já, as informaçóes referentes aos indicadores de desempenho não financeiros foram coletadas nos relatórios anuais, de administração e sustentabilidade evidenciados pelas organizaçóes. Para que a missão seja efetiva e seja útil para nortear o planejamento estratégico, ela deve apresentar alguns elementos básicos (Pearce, 1982). Para o delineamento das características presentes na missão institucional declarada pelas empresas, tomou-se por base as características apresentadas nos estudos de Pearce e David (1987) e David (1989). Essas características foram utilizadas para nortear a análise de conteúdo, e são apresentadas na tabela 2 .

Considerou-se como missão declarada pela empresa, aquela publicada no seu site oficial ou em seus relatórios anuais e de sustentabilidade. Assim, foi analisado se as missóes evidenciadas pelas empresas continham as características de análise supracitadas (respondendo aos questionamentos). As características da missão 
foram tabuladas de forma binária. Isto é, foi verificado a presença de cada uma das características nas missóes institucionais divulgadas pela empresa, atribuindo-se valor 1 (um) quando a característica estava presente na missão, e 0 (zero) caso contrário.

\section{Tabela 2. Características que a missáo deve conter e esclarecimento das características}

\begin{tabular}{|c|c|c|}
\hline & Características da missão & $\begin{array}{l}\text { Esclarecimento das } \\
\text { características }\end{array}$ \\
\hline $\mathrm{C} 1$ & $\begin{array}{l}\text { Definição dos clientes e } \\
\text { mercado alvo }\end{array}$ & $\begin{array}{l}\text { Quem são os clientes-alvo da } \\
\text { empresa? }\end{array}$ \\
\hline $\mathrm{C} 2$ & $\begin{array}{l}\text { Definição dos produtos ou } \\
\text { serviços oferecidos }\end{array}$ & $\begin{array}{l}\text { Quais são os principais pro- } \\
\text { dutos ou serviços da empresa? }\end{array}$ \\
\hline $\mathrm{C} 3$ & $\begin{array}{l}\text { Definiçáo do domínio } \\
\text { geográfico }\end{array}$ & $\begin{array}{l}\text { Onde a empresa pretende } \\
\text { competir? }\end{array}$ \\
\hline $\mathrm{C} 4$ & $\begin{array}{l}\text { Definição das tecnologias } \\
\text { essenciais }\end{array}$ & $\begin{array}{l}\text { Qual é a tecnologia essencial } \\
\text { da empresa? }\end{array}$ \\
\hline $\mathrm{C} 5$ & $\begin{array}{l}\text { Expressáo do compromisso } \\
\text { com a sobrevivência, cres- } \\
\text { cimento e lucratividade }\end{array}$ & $\begin{array}{l}\text { Qual é o compromisso da } \\
\text { empresa com seus objetivos } \\
\text { econômicos? }\end{array}$ \\
\hline $\mathrm{C} 6$ & $\begin{array}{l}\text { Declaração dos elemen- } \\
\text { tos chave na filosofia da } \\
\text { organizaçáo }\end{array}$ & $\begin{array}{l}\text { Quais são as crenças básicas, } \\
\text { valores, aspiraçôes e priorida- } \\
\text { des filosóficas da empresa? }\end{array}$ \\
\hline C7 & $\begin{array}{l}\text { Identificação do auto- } \\
\text { conceito }\end{array}$ & $\begin{array}{l}\text { Quais são os principais } \\
\text { pontos fortes e vantagens } \\
\text { competitivas? }\end{array}$ \\
\hline $\mathrm{C} 8$ & $\begin{array}{l}\text { Definição da imagem } \\
\text { pública desejada }\end{array}$ & $\begin{array}{l}\text { Quais são as responsabilida- } \\
\text { des públicas e que imagem } \\
\text { pública é desejada? }\end{array}$ \\
\hline C9 & $\begin{array}{l}\text { Preocupaçáo com os fun- } \\
\text { cionários }\end{array}$ & $\begin{array}{l}\text { Qual é a atitude da empresa } \\
\text { com relação aos seus funcio- } \\
\text { nários? }\end{array}$ \\
\hline
\end{tabular}

Fonte: Pearce e David (1987) e David (1989).

Além das características da missão, foi verificada a evidenciação dos indicadores de desempenho não financeiros por parte das empresas analisadas. Como a literatura não aponta nenhum conjunto específico de indicadores de desempenho (Callado et al., 2015; Vargas et al., 2016), para fins da presente pesquisa foram utilizados os indicadores não financeiros adotados nas

pesquisas de Marquezan et al. (2013) e Vargas et al. (2016). Optou-se por adotar estes indicadores tendo em vista que se alinham ao objetivo da pesquisa, possibilitando a coleta por meio de dados secundários, e por terem sido validados em pesquisas anteriores, dando maior robustez aos resultados encontrados. Os indicadores são apresentados na tabela 3 .

Tabela 3. Indicadores de desempenho náo financeiros

\begin{tabular}{|c|c|}
\hline $\begin{array}{l}\text { Categorias de } \\
\text { indicadores }\end{array}$ & Indicadores pesquisados \\
\hline Qualidade & $\begin{array}{l}\text { 1. Açôes realizadas para melhoria na pres- } \\
\text { tação de serviço, produção e comércio. }\end{array}$ \\
\hline $\begin{array}{l}\text { Perspectiva } \\
\text { ambiental }\end{array}$ & $\begin{array}{l}\text { 1. Recuperação de áreas de preservação } \\
\text { ambiental; } \\
\text { 2. Redução no consumo de recursos } \\
\text { naturais; } \\
\text { 3. Relacionamento com stakeholders. }\end{array}$ \\
\hline $\begin{array}{l}\text { Perspectiva do } \\
\text { cliente }\end{array}$ & $\begin{array}{l}\text { 1. Número de clientes; } \\
\text { 2. Índices de satisfação de clientes; } \\
\text { 3. Atendimento ao cliente. }\end{array}$ \\
\hline $\begin{array}{l}\text { Perspectiva de } \\
\text { produtos/ser- } \\
\text { viços }\end{array}$ & $\begin{array}{l}\text { 1. Pontos de venda; } \\
\text { 2. Volume vendido; } \\
\text { 3. Gestão de fornecedores. }\end{array}$ \\
\hline $\begin{array}{l}\text { Perspectiva } \\
\text { social }\end{array}$ & $\begin{array}{l}\text { 1. Número de projetos sociais; } \\
\text { 2. Abrangência dos projetos sociais. }\end{array}$ \\
\hline Processos & $\begin{array}{l}\text { 1. Melhorias nos processos; } \\
\text { 2. Captaçáo e/ou processamento de } \\
\text { matérias-primas; } \\
\text { 3. Utilização da capacidade instalada; } \\
\text { 4. Horas de treinamento dos funcionários } \\
\text { 5. Logística. }\end{array}$ \\
\hline Pessoas & $\begin{array}{l}\text { 1. Número de empregados, rotatividade, } \\
\text { escolaridade, faixa etária, número de } \\
\text { empregados por gênero, mulheres em } \\
\text { cargo de gerência/diretoria. }\end{array}$ \\
\hline Imagem & $\begin{array}{l}\text { 1. Informaçóes relativas à imagem da } \\
\text { empresa: reconhecimentos, prêmios e } \\
\text { certificaçóes por institutos, universida- } \\
\text { des, revistas, pesquisas de imagem, etc. }\end{array}$ \\
\hline
\end{tabular}

Fonte: Adaptado de Marquezan et al. (2013) e Vargas et al. (2016). 
Cumpre ressaltar que para fins desta pesquisa, partiu-se da premissa de que as empresas evidenciam os indicadores que são utilizadas por elas. Assim, utilizou-se das palavras-chave para representar os diferentes indicadores de desempenho não financeiros de modo a verificar a evidenciação e utilização destes por parte das empresas analisadas. Os indicadores foram categorizados de forma binária, a qual foi atribuído valor 1 (um) se a empresa evidenciasse a respectiva prática em seus relatórios e 0 (zero) caso contrário.

Para tratamento estatístico dos dados coletados, foi adotada a Prova Exata de Fisher. Esse teste é útil para analisar a relevância da associação entre duas variáveis categóricas (Callado \& Jack, 2017), ou seja, quando se busca analisar a significância da relação entre duas variáveis qualitativas que só podem assumir dois valores cada (Pereira \& Romão, 2015). Para tanto, verificou-se individualmente a associação das características da missão com os indicadores de desempenho não financeiros. Considerando o nível de significância de $95 \%$ como forma de constatação da existência de associação $(\mathrm{p}=0,05)$.

\section{Análise e discussão dos resultados}

Inicialmente, os dados coletados foram analisados por meio de estatística descritiva. Na tabela 4 são apresentadas as características presentes na missão institucional das empresas analisadas.

Por meio dos resultados obtidos, verificou-se que, de modo geral, as missóes das empresas analisadas apresentam baixo alinhamento (compliance) em relação às características propostas por Pearce e David (1987) e David (1989), uma vez que dois terços das características referentes à missão das empresas apresentaram percentuais de conformidade inferiores a 50\%. Por outro lado, percebe-se uma grande ênfase nas características referentes à definição dos produtos ou serviços oferecidos, à filosofia da organização e à definição da imagem pública desejada, que apresentaram um maior alinhamento as características propostas (mais de 60\% das missóes). Característica relativa ao compromisso da empresa com a sobrevivência e lucratividade foi identificada na missão de aproximadamente $50 \%$ das

Tabela 4. Características da missão institucional apresentadas pelas companhias brasileiras de capital aberto (2018)

\begin{tabular}{|c|c|c|c|c|c|c|}
\hline \multirow{2}{*}{ Características da missão institucional } & \multicolumn{2}{|c|}{ Apresenta } & \multicolumn{2}{|c|}{ Náo Apresenta } & \multicolumn{2}{|c|}{ Total } \\
\hline & Frequência & $\%$ & Frequência & $\%$ & Frequência & $\%$ \\
\hline Clientes e mercado alvo & 18 & 15,65 & 97 & 84,35 & 115 & 100 \\
\hline Produtos ou serviços oferecidos & 71 & 61,74 & 44 & 38,26 & 115 & 100 \\
\hline Domínio geográfico & 28 & 24,35 & 87 & 75,65 & 115 & 100 \\
\hline Tecnologias essenciais & 29 & 25,22 & 86 & 74,78 & 115 & 100 \\
\hline Sobrevivência, crescimento e lucratividade & 57 & 49,57 & 58 & 50,43 & 115 & 100 \\
\hline Filosofia da organização & 72 & 62,61 & 43 & 37,39 & 115 & 100 \\
\hline Identificação do autoconceito & 34 & 29,57 & 81 & 70,43 & 115 & 100 \\
\hline Imagem pública desejada & 77 & 66,96 & 38 & 33,04 & 115 & 100 \\
\hline Preocupação com os funcionários & 24 & 20,87 & 91 & 79,13 & 115 & 100 \\
\hline
\end{tabular}

Fonte: Dados da pesquisa. 
empresas analisadas. Estes resultados vão ao encontro dos encontrados na pesquisa de Mussoi et al. (2011) a qual verificaram que estes elementos estáo entre os mais evidenciados nas missóes das empresas amostra analisadas.

Gonzaga et al. (2015) constataram a presença dos elementos relacionados a imagem pública desejada, e a preocupação com a sobrevivência e lucratividade em grande parte das missōes analisadas. Do mesmo modo, as características relacionadas aos produtos e serviços oferecidos, bem como a preocupação da empresa com a sobrevivência e lucratividade fizeram-se presentes em grande parte das missóes analisadas nos estudos de Lugoboni et al. (2019) e Martins et al. (2018), sendo que este último analisou diferentes países. Em seu estudo Biloslavo (2004) verificou que as características relacionadas aos produtos e serviços oferecidos estavam presentes em grande parte das missões analisadas.

Entre as características menos presentes nas missóes estão os clientes e mercado alvo, preocupação com os funcionários, domínio geográfico e tecnologias, respectivamente. Esses resultados corroboram o encontrado por Gonzaga et al. (2015). A baixa presença do elemento tecnologia nas missóes evidenciadas, também foi observado em outras pesquisas (Biloslavo, 2004; Mussoi et al., 2011; King et al., 2012; Martins et al., 2018). Demonstrando que alguns dos achados desta pesquisa estão alinhados a evidências encontradas em diferentes contextos estudados. Ressalta-se que desde Pearce e David (1987) e David (1989) ocorreram mudanças nos elementos chave das missôes empresariais. A tecnologia, por exemplo, deixou de ser uma preocupação central tendo em vista que no cenário atual ela passa a ser um elemento "obrigatório" para competitividade organizacional (Martins et al., 2018).
No tocante as características propostas por Pearce e David (1987) e David (1989), observa-se na tabela 5 que nenhuma missão analisada apresentou todas as características, que são esperadas em uma missão efetiva. Verifica-se que, a maioria das missóes apresentaram entre três e quatro características, demonstrando que as missóes evidenciadas pelas empresas brasileiras apresentam baixa efetividade (compliance) a luz do que foi proposto pelos autores supracitados. Apenas duas empresas apresentaram sete características, sendo que nenhuma empresa analisada apresentou oito ou nove características em sua missão institucional.

Tabela 5. Efetividade das missóes (2018)

\begin{tabular}{|l|c|}
\hline \multicolumn{1}{|c|}{ Efetividade } & Observaçóes \\
\hline $\mathbf{9}$ características & - \\
\hline $\mathbf{8}$ características & - \\
\hline 7 características & 2 \\
\hline 6 características & 6 \\
\hline 5 características & 22 \\
\hline 4 características & 27 \\
\hline 3 características & 34 \\
\hline 2 características & 16 \\
\hline 1 características & 8 \\
\hline Total de empresas & 115 \\
\hline
\end{tabular}

Fonte: Dados da pesquisa.

Os resultados encontrados na tabela 5 se alinham aos achados evidenciados em estudos anteriores, que verificaram um baixo alinhamento entre a missão institucional de empresas brasileiras, e as características propostas pela literatura (Mussoi et al., 2011; Lugoboni et al., 2019; Gonzaga et al., 2015; Martins et al., 2018). Mussoi et al. (2011) chamam a atenção para o fato de as empresas brasileiras usarem a missão institucional mais como uma ferramenta de marketing do que como uma ferramenta que auxilia no planejamento estratégico empresarial, e criticam, ainda, a 
forma genérica como a maioria das missóes são evidenciadas, destinando-se a valorizar a imagem da empresa junto aos stakeholders. Na tabela 6 são apresentados os indicadores de desempenho náo financeiros utilizados pelas companhias objeto de análise.
A partir dos resultados obtidos, é possível verificar que o indicador de desempenho mais utilizado pelas empresas estudadas foi o indicador relacionado às pessoas que fazem parte da organização, evidenciado por aproximadamente $70 \%$ das empresas. Também,

Tabela 6. Indicadores de desempenho não financeiros utilizados pelas companhias brasileiras de capital aberto (2018)

\begin{tabular}{|c|c|c|c|c|c|c|}
\hline \multirow{2}{*}{ Indicadores } & \multicolumn{2}{|c|}{ Utiliza } & \multicolumn{2}{|c|}{ Não utiliza } & \multicolumn{2}{|c|}{ Total } \\
\hline & Qtd. & $\%$ & Qtd. & $\%$ & Qtd. & $\%$ \\
\hline $\begin{array}{l}\text { Qualidade } \\
\text { Melhoria na prestaçáo de serviço, produção e comércio }\end{array}$ & 59 & 51,30 & 56 & 48,70 & 115 & 100 \\
\hline $\begin{array}{l}\text { Perspectiva ambiental } \\
\text { Recuperaçáo de áreas } \\
\text { Reduçáo do consumo de recursos naturais } \\
\text { Relacionamento com stakeholders }\end{array}$ & $\begin{array}{l}48 \\
61 \\
52\end{array}$ & $\begin{array}{l}41,74 \\
53,04 \\
45,22 \\
\end{array}$ & $\begin{array}{l}67 \\
54 \\
63\end{array}$ & $\begin{array}{l}58,26 \\
46,96 \\
54,78\end{array}$ & $\begin{array}{l}115 \\
115 \\
115 \\
\end{array}$ & $\begin{array}{l}100 \\
100 \\
100 \\
\end{array}$ \\
\hline $\begin{array}{l}\text { Perspectiva do cliente } \\
\text { Número de clientes } \\
\text { Índices de satisfaçáo de clientes } \\
\text { Atendimento ao cliente }\end{array}$ & $\begin{array}{l}41 \\
34 \\
58\end{array}$ & $\begin{array}{l}35,65 \\
29,57 \\
50,43\end{array}$ & $\begin{array}{l}74 \\
81 \\
57\end{array}$ & $\begin{array}{l}64,35 \\
70,43 \\
49,57\end{array}$ & $\begin{array}{l}115 \\
115 \\
115\end{array}$ & $\begin{array}{l}100 \\
100 \\
100\end{array}$ \\
\hline $\begin{array}{l}\text { Perspectiva de produtos/serviços } \\
\text { Pontos de venda } \\
\text { Volume vendido } \\
\text { Gestáo de Fornecedores }\end{array}$ & $\begin{array}{l}32 \\
37 \\
50\end{array}$ & $\begin{array}{l}27,83 \\
32,17 \\
43,48\end{array}$ & $\begin{array}{l}83 \\
78 \\
65\end{array}$ & $\begin{array}{l}72,17 \\
67,83 \\
56,52\end{array}$ & $\begin{array}{l}115 \\
115 \\
115\end{array}$ & $\begin{array}{l}100 \\
100 \\
100\end{array}$ \\
\hline Perspectiva social & & & & & & \\
\hline $\begin{array}{l}\text { Número de projetos sociais } \\
\text { Abrangência dos projetos sociais }\end{array}$ & $\begin{array}{l}59 \\
51\end{array}$ & $\begin{array}{l}51,30 \\
44,35\end{array}$ & $\begin{array}{l}56 \\
64\end{array}$ & $\begin{array}{l}48,70 \\
55,65\end{array}$ & $\begin{array}{l}115 \\
115\end{array}$ & $\begin{array}{l}100 \\
100\end{array}$ \\
\hline $\begin{array}{l}\text { Processos } \\
\text { Melhorias nos processos } \\
\text { Utilizaçáo da capacidade instalada } \\
\text { Horas de treinamento de funcionários } \\
\text { Captação/Processamento de matérias-primas } \\
\text { Logística } \\
\text { Pessoas }\end{array}$ & $\begin{array}{l}64 \\
43 \\
52 \\
14 \\
34\end{array}$ & $\begin{array}{l}55,65 \\
37,39 \\
45,22 \\
12,17 \\
29,57\end{array}$ & $\begin{array}{c}51 \\
72 \\
63 \\
101 \\
81\end{array}$ & $\begin{array}{l}44,35 \\
62,61 \\
54,78 \\
87,83 \\
70,43\end{array}$ & $\begin{array}{l}115 \\
115 \\
115 \\
115 \\
115\end{array}$ & $\begin{array}{l}100 \\
100 \\
100 \\
100 \\
100\end{array}$ \\
\hline $\begin{array}{l}\text { Corpo funcional } \\
\text { Imagem }\end{array}$ & 79 & 68,70 & 36 & 31,30 & 115 & 100 \\
\hline Reconhecimento, prêmios, certificaçóes & 60 & 52,17 & 55 & 47,83 & 115 & 100 \\
\hline
\end{tabular}

Fonte: Dados da pesquisa. 
merecem destaque os indicadores referentes a melhorias nos processos $(55,65 \%)$, redução no consumo de recursos naturais $(53,04 \%)$ e imagem da empresa $(52,17 \%)$, que apresentaram um acentuado nível de utilização pelas empresas analisadas. Estes resultados se assemelham aos encontrados nas pesquisas de Marquezan et al. (2013) e Vargas et al. (2016), ao qual verificaram que a categoria de indicadores relacionadas as pessoas e a categoria de indicadores ambientais, são evidenciados com mais frequência pelas organizaçóes. Posteriormente, procedimentos estatísticos foram operacionalizados para analisar a significância das relaçóes entre o compliance da missão institucional e a utilização de indicadores de desempenho não financeiros. Os resultados encontram-se evidenciados na tabela 7.

\section{Tabela 7. Análise da significância estatística} das relaçóes entre as representaçóes da missão institucional e os indicadores de qualidade, pessoas e imagem (2018)

\begin{tabular}{|l|c|c|c|}
\hline \multicolumn{1}{|c|}{$\begin{array}{c}\text { Características da missão } \\
\text { institucional }\end{array}$} & Qualidade & Pessoas & Imagem \\
\hline Clientes e mercado alvo & 0,55 & 0,30 & 0,47 \\
\hline $\begin{array}{l}\text { Produtos ou serviços ofere- } \\
\text { cidos }\end{array}$ & 0,13 & $0,02^{* *}$ & 0,28 \\
\hline Domínio geográfico & $0,00^{*}$ & 0,20 & 0,08 \\
\hline Tecnologias essenciais & 0,43 & 0,13 & 0,06 \\
\hline $\begin{array}{l}\text { Sobrevivência, crescimento e } \\
\text { lucratividade }\end{array}$ & 0,15 & 0,25 & 0,46 \\
\hline Filosofia da organizaçáo & 0,53 & 0,34 & 0,35 \\
\hline $\begin{array}{l}\text { Identificação do auto- } \\
\text { conceito }\end{array}$ & $0,02^{* *}$ & $0,04^{* *}$ & $0,04^{* *}$ \\
\hline Imagem pública desejada & 0,21 & 0,43 & 0,34 \\
\hline $\begin{array}{l}\text { Preocupaçáo com os funcio- } \\
\text { nários }\end{array}$ & 0,46 & 0,06 & 0,42 \\
\hline
\end{tabular}

Nota: * e ${ }^{* *}$ Significância a $1 \%$ e $5 \%$, respectivamente. Fonte: Dados da pesquisa.
Os resultados obtidos apontam evidências acerca da presença de algumas relações estatisticamente significativas entre as características da missão institucional evidenciada pelas empresas e os indicadores de desempenho referentes à qualidade, pessoas e imagem. Verifica-se que, a identificação do autoconceito se mostrou relacionado de maneira significativa com os três indicadores testados. Assim, aquelas empresas que evidenciam em sua missão seus principais pontos fortes e vantagens competitivas, preocupam-se em acompanhar o desempenho em áreas como a qualidade dos produtos/serviços oferecidos, a qualidade do seu quadro funcional, bem como a sua imagem perante as partes interessadas. Sinalizando que as organizaçóes desejam alcançar e preservar estes objetivos ao longo do tempo.

Do mesmo modo, a característica relacionada à definição de produto/serviço apresentou associação significativa para os indicadores relacionados às pessoas. Este resultado indica que para as empresas que desejam focar em seus principais produtos e serviços, torna-se relevante acompanhar seu quadro funcional. Além disso, a definição do domínio geográfico se mostrou associado de maneira significativa à qualidade. Desse modo, as empresas que evidenciam em sua missão os mercados onde almejam competir tendem a fazer um maior uso de indicadores que acompanhem as melhorias na qualidade dos produtos ou serviços. Talvez com o intuito de alcançar os padróes de qualidade exigidos para este ambiente. $\mathrm{Na}$ tabela 8, são apresentadas as relaçóes entre as representaçôes da missão institucional e os indicadores ambientais. Os resultados mostram que não há associação entre estas variáveis. Indicando que as empresas analisadas não fazem uso de indicadores ambientais para o compliance dos objetivos expressos na missão. 
Tabela 8. Análise da significância estatística das relaçóes entre as representaçóes da missáo institucional e os indicadores ambientais (2018)

\begin{tabular}{|l|c|c|c|}
\hline \multicolumn{1}{|c|}{$\begin{array}{c}\text { Características da } \\
\text { missáo Institucional }\end{array}$} & $\begin{array}{c}\text { Recu- } \\
\text { peraçáo } \\
\text { de áreas } \\
\text { degradadas }\end{array}$ & $\begin{array}{c}\text { Redução no } \\
\text { consumo } \\
\text { de recursos } \\
\text { naturais }\end{array}$ & $\begin{array}{c}\text { Relaciona- } \\
\text { mento com } \\
\text { stakeholders }\end{array}$ \\
\hline $\begin{array}{l}\text { Clientes e mercado } \\
\text { alvo }\end{array}$ & 0,50 & 0,48 & 0,57 \\
\hline $\begin{array}{l}\text { Produtos ou serviços } \\
\text { oferecidos }\end{array}$ & 0,36 & 0,37 & 0,09 \\
\hline Domínio geográfico & 0,16 & 0,07 & 0,17 \\
\hline Tecnologias essenciais & 0,24 & 0,51 & 0,06 \\
\hline $\begin{array}{l}\text { Sobrevivência, cresci- } \\
\text { mento e lucratividade }\end{array}$ & 0,54 & 0,39 & 0,39 \\
\hline $\begin{array}{l}\text { Filosofia da organi- } \\
\text { zaçáa }\end{array}$ & 0,28 & 0,30 & 0,12 \\
\hline $\begin{array}{l}\text { Identificaçáo do } \\
\text { autoconceito }\end{array}$ & 0,24 & 0,07 & 0,06 \\
\hline $\begin{array}{l}\text { Imagem pública } \\
\text { desejada }\end{array}$ & 0,44 & 0,14 & 0,39 \\
\hline $\begin{array}{l}\text { Preocupaçáo com os } \\
\text { funcionários }\end{array}$ & 0,06 & 0,36 & 0,22 \\
\hline
\end{tabular}

Fonte: Dados da pesquisa.

Em seguida, foram testadas individualmente as relações entre as características da missão e os indicadores da perspectiva de clientes, cujos resultados são apresentados na tabela 9 .

Com base nos resultados obtidos, é possível constatar a existência de associaçôes significativas entre as características expressas na missão, referentes aos produtos/ serviços e a definição de tecnologias essenciais, com o indicador que mede o número de clientes. Permitindo inferir que para as empresas que evidenciam em suas missóes os produtos e/ou serviços oferecidos, assim como as tecnologias essenciais ao negócio este indicador é considerado relevante para auxiliar no alcance destes objetivos.
Tabela 9. Análise da significância estatística das relaçóes entre as representaçóes da missão institucional e os indicadores de clientes (2018)

\begin{tabular}{|l|c|c|c|}
\hline $\begin{array}{c}\text { Características da missáo } \\
\text { Institucional }\end{array}$ & $\begin{array}{c}\text { Número } \\
\text { de clientes }\end{array}$ & $\begin{array}{c}\text { Índices de } \\
\text { satisfaçáo } \\
\text { de clientes }\end{array}$ & $\begin{array}{c}\text { Atendi- } \\
\text { mento ao } \\
\text { cliente }\end{array}$ \\
\hline Clientes e mercado alvo & 0,31 & 0,24 & 0,38 \\
\hline $\begin{array}{l}\text { Produtos ou serviços } \\
\text { oferecidos }\end{array}$ & $0,00^{*}$ & 0,41 & 0,15 \\
\hline Domínio geográfico & 0,12 & $0,03^{* *}$ & 0,39 \\
\hline Tecnologias essenciais & $0,03^{* *}$ & 0,07 & 0,47 \\
\hline $\begin{array}{l}\text { Sobrevivência, cresci- } \\
\text { mento e lucratividade }\end{array}$ & 0,37 & 0,39 & 0,46 \\
\hline Filosofia da organizaçáo & 0,10 & 0,53 & 0,37 \\
\hline $\begin{array}{l}\text { Identificaçáo do auto- } \\
\text { conceito }\end{array}$ & 0,13 & $0,01^{*}$ & 0,06 \\
\hline Imagem pública desejada & 0,17 & 0,37 & 0,14 \\
\hline $\begin{array}{l}\text { Preocupaçáo com os } \\
\text { funcionários }\end{array}$ & 0,10 & 0,38 & 0,39 \\
\hline
\end{tabular}

Nota: * $e^{* *}$ Significância a $1 \%$ e $5 \%$, respectivamente.

Fonte: Dados da pesquisa.

Observa-se ainda associações significativas entre as características relativas à definição do domínio geográfico e a identificação do autoconceito da missão institucional e o indicador de satisfação de clientes. Assim, os resultados mostram que as organizaçóes que evidenciam onde desejam competir, bem como seus principais pontos fortes, podem estar avaliando o nível de satisfação dos clientes para acompanharem se estão no caminho certo e a necessidade de melhorias. Pois, para o sucesso no longo prazo, a empresa deve encontrar meios para assegurar a manutenção desta boa gestão. Nesse sentido, a satisfação dos clientes é fator relevante. $\mathrm{Na}$ tabela 10 estáo apresentados os resultados acerca das relaçóes entre a missão institucional e os indicadores de produto. Como pode ser observado, não foram encontradas relações estatisticamente significativas entre estas variáveis. 
Tabela 10. Análise da significância estatística

das relaçóes entre as representaçóes da missão institucional e os indicadores de produtos (2018)

\begin{tabular}{|l|c|c|c|}
\hline $\begin{array}{c}\text { Características da missáo } \\
\text { institucional }\end{array}$ & $\begin{array}{c}\text { Pontos } \\
\text { de venda }\end{array}$ & $\begin{array}{c}\text { Volume } \\
\text { vendido }\end{array}$ & $\begin{array}{c}\text { Informaçóes } \\
\text { sobre forne- } \\
\text { cedores }\end{array}$ \\
\hline Clientes e mercado alvo & 0,19 & 0,34 & 0,56 \\
\hline $\begin{array}{l}\text { Produtos ou serviços } \\
\text { oferecidos }\end{array}$ & 0,45 & 0,55 & 0,15 \\
\hline Domínio geográfico & 0,20 & 0,41 & 0,38 \\
\hline Tecnologias essenciais & 0,10 & 0,09 & 0,08 \\
\hline $\begin{array}{l}\text { Sobrevivência, cresci- } \\
\text { mento e lucratividade }\end{array}$ & 0,28 & 0,10 & 0,54 \\
\hline Filosofia da organizaçáo & 0,14 & 0,13 & 0,19 \\
\hline $\begin{array}{l}\text { Identificaçáo do auto- } \\
\text { conceito }\end{array}$ & 0,12 & 0,34 & 0,08 \\
\hline Imagem pública desejada & 0,50 & 0,38 & 0,20 \\
\hline $\begin{array}{l}\text { Preocupaçáo com os fun- } \\
\text { cionários }\end{array}$ & 0,52 & 0,34 & 0,16 \\
\hline
\end{tabular}

Fonte: Dados da pesquisa.

Prosseguiu-se a análise avaliando a existência de relações entre as representações da missão institucional e os indicadores sociais, conforme tabela 11 .

Os resultados obtidos apontam evidências sobre associaçóes entre a definição das tecnologias essenciais ao negócio e os indicadores de desempenho que medem o número de projetos sociais e a abrangência destes. Além disso, foi verificado que a definição da imagem pública desejada, se mostrou significativamente relacionado ao o indicador que mede a abrangência dos projetos sociais. Este resultado permite afirmar que, para as empresas que possuem como uma de suas prioridades serem vistas de forma positiva pelas partes interessadas, a abrangência dos projetos sociais pode ser uma importante ferramenta para que isto ocorra. Por fim, realizou-se a análise das relaçóes entre as representaçóes da missão institucional e os indicadores de processos, conforme mostra a tabela 12 .
Tabela 11. Análise da significância estatística das relaçóes entre as representaçóes da missão institucional e os indicadores sociais (2018)

\begin{tabular}{|l|c|c|}
\hline \multicolumn{1}{|c|}{$\begin{array}{c}\text { Características da missão } \\
\text { institucional }\end{array}$} & $\begin{array}{c}\text { Número de } \\
\text { projetos sociais }\end{array}$ & $\begin{array}{c}\text { Abrangência } \\
\text { dos projetos } \\
\text { sociais }\end{array}$ \\
\hline Clientes e mercado alvo & 0,35 & 0,59 \\
\hline $\begin{array}{l}\text { Produtos ou serviços ofe- } \\
\text { recidos }\end{array}$ & 0,21 & 0,06 \\
\hline Domínio geográfico & 0,20 & 0,34 \\
\hline Tecnologias essenciais & $0,02^{* *}$ & $0,02^{* *}$ \\
\hline $\begin{array}{l}\text { Sobrevivência, crescimento } \\
\text { e lucratividade }\end{array}$ & 0,25 & 0,56 \\
\hline Filosofia da organização & 0,56 & 0,31 \\
\hline $\begin{array}{l}\text { Identificaçáo do auto- } \\
\text { conceito }\end{array}$ & 0,21 & 0,25 \\
\hline Imagem pública desejada & 0,06 & $0,04^{* *}$ \\
\hline $\begin{array}{l}\text { Preocupaçáo com os fun- } \\
\text { cionários }\end{array}$ & 0,07 & 0,19 \\
\hline
\end{tabular}

Nota: * e** Significância a $1 \%$ e 5\%, respectivamente.

Fonte: Dados da pesquisa.

Os resultados apontam a existência de relaçóes significativas entre a missão e alguns dos indicadores testados. Como pode ser observado, a definição do domínio geográfico e a imagem pública desejada relacionam-se com o indicador de desempenho relacionado à logística. Da mesma forma, foi constatado que a definição das tecnologias essenciais apresenta associação estatisticamente significativa com o indicador de desempenho que monitora a utilização da capacidade instalada. Além disso, percebe-se uma relação significativa entre a identificação do autoconceito e o indicador que monitora melhorias no processo produtivo, sugerindo que as empresas que evidenciam em sua missão os principais pontos fortes, preocupam-se em acompanhar as melhorias realizadas em seus processos, buscando manter seus pontos fortes evidenciados ao longo do tempo. 
Tabela 12. Análise da significância estatística das relaçóes entre as representaçóes da missão institucional e os indicadores de processos (2018)

\begin{tabular}{|l|c|c|c|c|c|}
\hline Características da missão institucional & $\begin{array}{c}\text { Melhorias } \\
\text { no processo }\end{array}$ & $\begin{array}{c}\text { Utilizaçáo da } \\
\text { capacidade instalada }\end{array}$ & $\begin{array}{c}\text { Horas de treinamento } \\
\text { de funcionários }\end{array}$ & $\begin{array}{c}\text { Captaçáo de } \\
\text { matérias-primas }\end{array}$ & Logística \\
\hline Clientes e mercado alvo & 0,40 & 0,07 & 0,19 & 0,31 & 0,55 \\
\hline Produtos ou serviços oferecidos & 0,35 & 0,06 & 0,17 & 0,31 & 0,58 \\
\hline Domínio geográfico & 0,48 & 0,36 & 0,17 & 0,35 & $0,02^{* *}$ \\
\hline Tecnologias essenciais & 0,56 & $0,02^{* *}$ & 0,06 & 0,49 & 0,50 \\
\hline Sobrevivência, crescimento e lucratividade & 0,46 & 0,47 & 0,54 & 0,59 & 0,55 \\
\hline Filosofia da organizaçáo & 0,15 & 0,28 & 0,35 & 0,33 & 0,17 \\
\hline Identificaçáo do autoconceito & $0,00^{*}$ & 0,12 & 0,06 & 0,15 & 0,24 \\
\hline Imagem pública desejada & 0,17 & 0,13 & 0,07 & 0,51 & $0,04^{* *}$ \\
\hline Preocupação com os funcionários & 0,30 & 0,23 & 0,22 & 0,32 & 0,11 \\
\hline
\end{tabular}

Nota: ${ }^{*} \mathrm{e}^{* *}$ Significância a $1 \%$ e $5 \%$, respectivamente.

Fonte: Dados da pesquisa.

Portanto, observa-se que os resultados confirmaram a presença de associaçóes estatisticamente significativas entre o compliance da missão institucional e a utilização de indicadores de desempenho não financeiros no âmbito das empresas listadas na B3. Sinalizando que as empresas analisadas podem fazer uso destes indicadores para que possam medir o compliance de determinados objetivos e estratégias declaradas na missão institucional. Estes resultados contrastam os resultados encontrados na pesquisa de Gonzaga et al. (2015), ao qual não encontraram associação entre a missão e os indicadores financeiros. $\mathrm{O}$ que indica que os gestores das empresas analisadas podem priorizar indicadores não financeiros em detrimento dos financeiros.

Assim, estes achados se alinham ao sugerido pela literatura que os indicadores não financeiros são melhores métricas de desempenho futuro que os indicadores financeiros (Atkinson et al., 2000), e que os princípios que surgem da estratégia não podem ser totalmente captados em sistemas tradicionais (Punniyamoorthy \& Murali, 2008). Dessa forma, considerando que as medidas de desempenho devem derivar das estratégias das organizaçóes onde forem aplicadas (Wegner \& Misocsky, 2010). É possível que os indicadores não financeiros sejam mais adequados para acompanhar o compliance dos objetivos evidenciados na missão. Portanto, com base nos resultados encontrados aceita-se, em partes, a hipótese de que há uma associação positiva entre a missão institucional e os indicadores de desempenho não financeiros.

\section{Conclusáo}

A missão declarada evidencia o objetivo e a visão da organização para o futuro (Green \& Medlin, 2003), e orienta o estabelecimento de metas e prioridades organizacionais (Mussoi et al., 2011). Para avaliar se o que foi divulgado na missão está sendo atingido, as empresas podem fazer uso de indicadores de desempenho (Gonzaga et al., 2015). Assim, partindo da premissa de que estas são ferramentas complementares, esta pesquisa buscou investigar a associação entre o compliance da missão institucional das empresas brasileiras de capital aberto e a utilização de indicadores de desempenho 
não financeiros. Para tanto, dados de 115 empresas não financeiras de capital aberto foram analisados.

Por meio da análise descritiva, verificou-se que as missōes das companhias analisadas apresentaram baixo nível de alinhamento (compliance) em relação às características propostas por Pearce e David (1987) e David (1989), demonstrando baixa efetividade nas missóes declaradas. De modo que, nenhuma missão apresentou todas as características propostas pela literatura. A maioria delas apresentaram entre três e quatro características. Em relação aos indicadores de desempenho não financeiros, verificou-se que os mais utilizados foram os relacionados às pessoas que fazem parte da organização (79\%), às melhorias nos processos $(64 \%)$, à redução no consumo de recursos naturais (61\%) e à imagem da empresa (60\%).

As evidências encontradas por meio da prova exata de fisher apontam para a presença de associações estatisticamente significativas entre a missão institucional e a utilização de indicadores de desempenho não financeiros. Estes resultados sugerem que as empresas analisadas fazem uso destes indicadores para acompanhar o compliance dos objetivos e estratégias declaradas em sua missão, embora nem todas as características da missão se relacionem com os indicadores não financeiros.

Desta forma, pode-se afirmar que o objetivo da pesquisa foi alcançado. Uma vez que, foi encontrado alinhamento entre o que a empresa declara como sendo importante e os indicadores utilizados para a avaliação de desempenho. Verifica-se ainda, que os resultados encontrados são coerentes, tendo em vista que nas variáveis em que foram encontradas relaçóes estatisticamente significativas, os indicadores não financeiros se mostram adequados para mensurar os objetivos evidenciados na missão.

Do ponto de vista teórico, o estudo contribui ao inserir uma nova perspectiva as pesquisas desenvolvidas

(a análise de indicadores de desempenho não financeiros) permitindo avançar em relação à literatura existente (que analisou indicadores financeiros), e fornecer novos insights para discussóes relacionadas ao tema. Do ponto de vista prático, estes resultados são importantes para as empresas ao reforçar a relevância da missão institucional para o alcance dos objetivos e estratégias empresariais. Demonstrando que os indicadores de desempenho não financeiros podem ser preferíveis para acompanhar se aquilo que foi declarado na missão está sendo alcançado. Além disso, as reflexões trazidas neste estudo podem ser de interesse para os investidores e para a sociedade em geral, à medida que permite verificar se as açôes das organizaçôes condizem com o que é divulgado na missão institucional. Esta informação pode complementar o processo decisório.

Tem-se como limitaçóes da pesquisa o fato de que os resultados de certa forma carregam a ontologia dos pesquisadores. Tendo em vista que, tanto as variáveis relacionadas a missão institucional, quanto as variáveis relacionadas aos indicadores de desempenho foram criadas por meio de análise de conteúdo. O que pode levar a uma compreensão divergente caso seja realizada por outro pesquisador. Além disso, a carência de estudos que associaram a missão aos indicadores de desempenho não financeiros, prejudicaram a comparação dos resultados. Portanto, quaisquer generalizaçóes que porventura venham a ser realizadas, devem considerar estas limitaçóes e as premissas adotadas no estudo.

Por se tratar de um campo de estudo pouco explorado, inúmeras são as possibilidades de pesquisas futuras. Estas poderão contribuir ao analisar outros países, utilizar dados primários por meio de questionários/entrevistas, adicionar novos indicadores não financeiros aos utilizados neste estudo, assim como outras características que a missão deve conter com base na literatura. 


\section{Referências}

Alegre, I., Berbegal-Mirabent, J., Guerrero, A., \& MasMachuca, M. (2018). The real mission of the mission statement: A systematic review of the literature. Journal of Management \& Organization, 24(4), 456-473. https://doi.org/10.1017/jmo.2017.82

Araújo, M.A., DeSouza Michelon, P., \&Lunkes, R. J. (2018). Missão institucional: Análise dos elementos de Pearce II (1982) na missão das universidades públicas brasileiras. Revista Ambiente Contábil, 10(2), 114-130. https:// doi.org/10.21680/2176-9036.2018v10n2ID13440

Assi, M. A. (2013). Gestão de compliance e seus desafios. São Paulo: Saint Paul.

Atkinson, A. A., Banker, R. D., Kaplan, R. S., Young, S. M. (2000). Contabilidade gerencial. São Paulo: Atlas.

Bardin, L. (2011). Análise de conteúdo. São Paulo: Ediçóes 70.

Bart, C. K. (1997). Industrial firms and the power of mission. Industrial Marketing Management, 26(4), 371-383. https://doi.org/10.1016/S0019-8501(96)00146-0

Bart, C. K., \& Baetz, M. C. (1998). The relationship between mission statements and firm performance: an exploratory study. Journal of Management Studies, 35(6), 823853. https://doi.org/10.1111/1467-6486.00121

Bartkus, B., Glassman, M., \& McAfee, B. (2006). Mission statement quality and financial performance. European Management Journal, 24(1), 86-94. https://doi. org/10.1016/j.emj.2005.12.010

Biloslavo, R. (2004). Web-based mission statements in Slovenian enterprises. Journal for East European Management Studies, 9(3) 265-277. https://doi. org/10.5771/0949-6181-2004-3-265

Bourne, M., Mills, J., Wilcox, M., Neely, A., \& Platts, K. (2000). Designing, implementing and updating performance measurement systems. International Journal of Operations \& Production Management, 20(7), 754771. https://doi.org/10.1108/01443570010330739
Callado, A. L. C., Callado, A. A. C., \& Almeida, M. A. (2008). A utilização de indicadores de desempenho não-financeiros em organizaçóes agroindustriais: um estudo exploratório. Organizaçôes Rurais \& Agroindustriais, $10(1), 35-48$.

Callado, A. A. C., Callado, A. L. C., \& Mendes, E. (2015). Padróes de uso de indicadores de desempenho: uma abordagem multivariada para empresas agroindustriais do setor avícola localizadas no estado de Pernambuco. Latin American Journal of Business Management, 6(2), 216-236. https://doi.org/10.13084/2175-8018/ijie. v6n11p348-366

Callado, A. A. C., Callado, A. L. C., Almeida, M. A., \& de Almeida Holanda, F. M. (2012). Relacionando fatores contingenciais com o uso de indicadores de desempenho em empresas do Porto Digital. Revista de Negócios, 17(3), 20-35. https://doi.org/10.7867/19804431.2012v17n3p20-35

Callado, A. A., \& Jack, L. (2017). Relations between usage patterns of performance indicators and the role of individual firms in fresh fruit agri-food supply chains. Journal of Applied Accounting Research, 18(3), 375398. https://doi.org/10.1108/JAAR-04-2016-0037

Candeloro, A. P. P., Rizzo, M. B. M. D., \& Pinho, V. (2012). Compliance 360\%: riscos, estratégias, conflitos e vaidades no mundo corporativo. São Paulo: Trevisan Editora Universitária.

Coral, S. M., Souza, P., \& Lunkes, R. J. (2013, 24-25 de outubro). Missão institucional: Análise dos principais elementos presentes nas missóes dos hotéis de Santa Catarina [Apresentação da conferência]. XVI Seminário em Administração SEMEAD. São Paulo, SP, Brasil.

Costa, S. C. (2012). O compliance como um novo modelo de negócio nas sociedades empresárias. Revista Cientifica da Faculdade Darcy Ribeiro, 3, 51-60.

David, F. R. (1989). How companies define their mission. Long Range Planning, 22(1), 90-97. https:/doi. org/10.1016/0024-6301(89)90055-1 
Diehl, C. A., Rech, M., \& Martins, V. Q. (2015, 29-31 de julho). Indicadores não-financeiros de avaliação de desempenho [Apresentação da conferência]. XVI Congresso USP de Controladoria e Contabilidade. São Paulo, SP, Brasil.

Duygulu, E., Ozeren, E., Iş̧1dar, P., \& Appolloni, A. (2016). The sustainable strategy for small and medium sized enterprises: The relationship between mission statements and performance. Sustainability, 8(7), 698-713. https://doi.org/10.3390/su8070698

Gil, C. A. (2017). Como elaborar projetos de pesquisa. São Paulo: Atlas.

Gonzaga, R. P., da Cruz, A. P. C., Pereira, C. A., \& Luz, A. T. M. da (2015). Associação entre missão institucional declarada por empresas brasileiras e seus indicadores de desempenho. Contabilidade Vista \& Revista, 26(1), 15-34.

Green Jr, K. W., \& Medlin, B. (2003). The strategic planning process: The link between mission statement and organizational performance. Academy of Strategic Management Journal, 2(1), 23-32.

Hronec, S. M. (1994). Sinais vitais: usando medidas de desempenho da qualidade, tempo e custos para traçar a rota para o futuro de sua empresa. São Paulo: Makron Books.

Kaplan, R. S., \& Norton, D. P. (1992). The balanced scorecard - measures that drive performance. Harvard Business Review, 71-79.

King, D. L., Case, Cki. J., \& Premo, K. M. (2012). An international mission statement comparison: United States, France, Germany, Japan, and China. Academy of Strategic Management Journal, 11(2), 93-136.

Lugoboni, L., Mello, D. A., Fischmann, A., Quishida, A., \& Zittei, M. V. (2019). A missão organizacional das melhores e maiores empresas do Brasil. Future Studies Research Journal: Trends \& Strategies, 11(1), 1-24. https://doi.org/10.24023/FutureJournal/2175-5825/2019.v11i1.281
Marquezan, L. H. F., Diehl, C. A., \& Alberton, J. R. (2013). Indicadores não financeiros de avaliação de desempenho: análise de conteúdo em relatórios anuais digitais. Contabilidade, Gestäo e Governança, 16(2), 46-61.

Martins, G. D. A., \& Theóphilo, C. R. (2009). Metodologia da investigação cientifica. São Paulo: Atlas.

Martins, G. A., \& Theóphilo, C. R. (2017). Metodologia da investigação cientifica para ciências sociais aplicadas. São Paulo: Atlas.

Martins, M. A. (2006). Avaliação de desempenho empresarial como ferramenta para agregar valor ao negócio. ConTexto, 6(10), 1-27.

Martins, V. G., Girão, L. F. D. A. P., da Cunha, A. C., \& Araújo, A. O. (2013). A utilização de modelos de avaliação de desempenho sob a perspectiva do GECON e do Balanced Scorecard: estudo de caso em uma central de cooperativas de crédito. Revista Evidenciação Contábil \& Finanças, 1(1), 99-117. https://doi. org/10.18405/recfin20130107

Martins, V. Q., Diehl, C. A., \& Brunozi Junior, A. C. (2018). Declaração de missão em países latinoamericanos: Efetividade e fatores contingenciais. Advances in Scientific \& Applied Accounting, 11(3), 464-483. https://doi.org/10.14392/ASAA.2018110306

Matias-Pereira, J. (2007). Manual de metodologia da pesquisa científica. São Paulo: Atlas.

Melo, H. P. A., \& Lima, A. C. (2019a). Da formalidade prescrita à cultura de integridade: escala de intensidade compliance como resposta às fraudes e riscos regulatórios no Brasil. Revista Ambiente Contábil-Universidade Federal do Rio Grande do Norte, 11(1), 280-304. https://doi.org/10.21680/21769036.2019v11n1ID15404

Melo, H. P. A., \& Lima, A. C. (2019b). Instituto compliance no brasil e a eficácia na mitigação ao risco corporativo. Revista Evidenciação Contábil \& Finanças, 7(3), 60-82. https://doi.org/10.22478/ufpb.2318$1001.2019 \mathrm{v} 7 \mathrm{n} 3.41536$

Contabilidad y Negocios (16) 32, 2021 / ISSN 1992-1896 
Miller, G. P. (2014). The compliance function: an overview (NYU Law and Economics Research Paper 393). New York: New York University.

Morais, E. J. (2005). Controles internos e estrutura de decisäo organizacional: o caso da Contadoria do Banco do Brasil (Dissertação de mestrado, Setor de Ciências Sociais Aplicadas, Universidade Federal do Paraná. Curitiba, Brasil).

Müller, C. J. (2003). Modelo de gestão integrando planejamento estratégico, sistemas de avaliação de desempenho e gerenciamento de processos (MEIO - Modelo de Estratégia, Indicadores e Operaçóes) (Tese de doutorado, Departamento de Engenharia de Produçáo e Transportes, Universidade Federal do Rio Grande do Sul. Porto Alegre, Brasil).

Mussoi, A., Lunkes, R. J., \& Da Silva, R. V. (2011). Missão institucional: uma análise da efetividade e dos principais elementos presentes nas missóes de empresas brasileiras de capital aberto. REGE-Revista de Gestão, 18(3), 361-384. https://doi.org/10.5700/rege431

Oliveira, M. C. D., Portella, A. R., Ferreira, D. D. M., \& Borba, J. A. (2016). Comunicaçấo de responsabilidade socioambiental na missão, visão e valores de empresas da BM \& FBovespa; e da Fortune 500. Contabilidade, Gestão e Governança, 19(2), 192-210. https://doi. org/10.21714/1984-3925_2016v19n2a2

Pearce, J. A. II. (1982). The company mission as a strategic tool. Sloan Management, 23(3), 15-24. https://doi. org/10.2307/41164965

Pearce, J. A., \& David, F. (1987). Corporate mission statements: The bottom line. Academy of Management Perspectives, 1(2), 109-115. https://doi.org/10.5465/ ame.1987.4275821

Pereira, A. L., \& Romão, A. L. (2015). A implementação do sistema de contabilidade de custos nos municípios portugueses. Revista Contemporânea de Contabilidade, 12(27), 165-186. https://doi.org/10.5007/2175$8069.2015 \mathrm{v} 12 \mathrm{n} 27 \mathrm{p} 165$
Perera, L. C. J., de Freitas, E. C., \& Imoniana, J. O. (2014). Avaliação do sistema de combate às fraudes corporativas no Brasil. Revista Contemporânea de Contabilidade, 11(23), 3-30. https://doi. org/10.5007/2175-8069.2014v11n23p3

Punniyamoorthy, M., \& Murali, R. (2008). Balanced score for the balanced scorecard: a benchmarking tool. Benchmarking: An International Journal, 15(4), 420-443. https://doi.org/10.1108/14635770810887230

Ribeiro, A. M., \& Carmo, C. H. S. do (2015). Planejamento estratégico e sustentabilidade: Uma análise da relação entre o conteúdo das missōes institucionais sua presença no índice de sustentabilidade da Bovespa. Revista de Gestão Social e Ambiental, 9(1), 19-35.

Ribeiro, M. C. P., \& Diniz, P. D. F. (2015). Compliance e lei anticorrupção nas empresas. Revista de Informação Legislativa, 52(205), 87-105.

Santos, E. F., Camacho, R. R., \& Junqueira, E. (2019,15-18 de junho). Declaraçôes de missōes na evidenciação da sobrevivência, crescimento e lucratividade das maiores empresas brasileiras [Apresentação da conferência]. XII Congresso ANPCONT. São Paulo, SP, Brasil.

Santos, R. A. D., Guevara, A. J. D. H., Amorim, M. C. S., $\&$ Ferraz-Neto, B. H. (2012). Compliance e liderança: a suscetibilidade dos líderes ao risco de corrupçáo nas organizaçóes. Einstein (São Paulo), 10(1), 1-10. https:// doi.org/10.1590/S1679-45082012000100003

Schramm, F. S. (2015). Instituição de programas de integridade (compliance): uma análise sob a ótica da Lei Federal 12.846/2013. Florianópolis: Portal Jurídico Investidura.

Silva, D. C., \& Covac, J. R. (2015). Compliance como boa prática de gestão no ensino superior privado. São Paulo: Saraiva.

Silva, G. R., Melo, H. P. A., \& Sousa, R. G. (2020). A influência do canal de denúncia anônima como instrumento de prevenção de riscos de compliance. Revista Evidenciação Contábil \& Finanças, 8(1), 21-39. https:// doi.org/10.22478/ufpb.2318-1001.2020v8n1.47857 
Vargas, S. B. D., Diehl, C. A., Ayres, P. R. R., \& Monteiro, A. F. (2016). Indicadores não-financeiros de avaliação de desempenho: análise de conteúdo em relatórios de administração de empresas de telecomunicaçóes. Sociedade, Contabilidade e Gestäo, 11(1), 84-102. https://doi.org/10.21446/scg_ufrj.v11i1.13374

Wanderer, L. C. (2017). A validação e a aderência à implementação do programa de compliance no sistema de crédito cooperativo (SICREDI) (Dissertação de mestrado, Escola de Administração, Universidade Federal do Rio Grande do Sul. Porto Alegre, Brasil).

Wegner, D., \& Misocsky, M. C. (2010). Avaliaçáo de desempenho de redes de pequenas empresas: contribuições da abordagem da produção de sentido. Organizaçôes \& Sociedade, 17, 345-361. https://doi. org/10.1590/S1984-92302010000200007
Wernke, R., \& Junges, I. (2017). Níveis de utilização e importância atribuídos aos indicadores não financeiros por empresas da região sul de Santa Catarina. Revista Contemporânea de Contabilidade, 14(33), 55-87. https://doi.org/10.5007/2175-8069.2017v14n33p55

Young, O.R. (1979). Compliance and Public Authority. Baltimore: Johns Hopkins University. Press.

Fecha de recepción: 04 de diciembre de 2020 Fecha de aceptación: 20 de julio de 2021 Correspondencia: diego.dantas.pb@gmail.com andrecallado@yahoo.com.br 